\title{
Interorgan Signaling following Pollination in Carnations
}

\author{
Michelle L. Jones ${ }^{1}$ and William R. Woodson ${ }^{2}$ \\ Department of Horticulture and Landscape Architecture, Purdue University, West Lafayette, IN 47907-1165
}

\begin{abstract}
AdDitional INDEX words. Dianthus caryophyllus, ethylene, ACC synthase, senescence
ABSTRACt. Following a compatible pollination in carnation (Dianthus caryophyllus L. 'White Sim'), a signal that coordinates postpollination events is translocated from the style to the ovary and petals. In this paper the roles of ethylene and its direct precursor, 1-aminocyclopropane-1-carboxylic acid (ACC), in this signaling were investigated. Following pollination, ethylene and ACC increased sequentially in styles, ovaries, and petals. Ethylene and ACC were highest initially in the stigmatic region of the style but by 24 hours after pollination were highest in the base. Activity of ACC synthase correlated well with ethylene production in styles and petals. In ovaries, ACC synthase activity decreased after pollination despite elevated ethylene production. Lack of ACC synthase activity in pollinated ovaries, coupled with high ACC content, suggests that $\mathrm{ACC}$ is translocated within the gynoecium. Further, detection of propylene from petals following application to the ovary provided evidence for movement of ethylene within the flower. Experiments that removed styles and petals at various times after pollination suggest there is a transmissible pollination signal in carnations that has reached the ovary by 12 hours and the petals by 14 to 16 hours.
\end{abstract}

The phytohormone ethylene has been implicated in the regulation of flower senescence (Burg and Dijkman, 1967; Kende and Baumgartner, 1974; Mayak et al., 1977). In carnation (Dianthus caryophyllus) flowers, senescence is characterized by a climacteric increase in ethylene biosynthesis that coincides with the first visual symptoms of senescence, petal inrolling (Borochov and Woodson, 1989; Nichols, 1966, 1971). In higher plants, ethylene is synthesized from methionine via a pathway involving the conversion of Sadenosylmethionine (SAM) to 1-amino-cyclopropane-1-carboxylic acid (ACC) and the oxidation of ACC to ethylene (Adams and Yang, 1979). The enzyme ACC synthase converts SAM to ACC while ACC oxidase catalyzes the conversion of ACC to ethylene. ACC synthase is generally considered to represent the rate-limiting step in the ethylene biosynthetic pathway (Kende, 1993; Yang and Hoffman, 1984).

In many flowers, pollination accelerates ethylene biosynthesis and developmental changes observed during the natural senescence of unpollinated flowers (Stead, 1992). While petal wilting and abscission are the most visual symptoms of pollination, an increase in ethylene biosynthesis from the stigma is the first detectable postpollination event in many species. This ethylene production occurs within a few hours after pollination, before pollen germination (Hoekstra and Weges, 1986; Larsen et al., 1995; Nichols, 1977; Nichols et al., 1983; O’Neill et al., 1993; Pech et al., 1987). The nature of the pollen-pistil interaction that induces this ethylene biosynthesis is unclear, but it is thought to coordinate postpollination development. Flowers that are insensitive to ethylene due to treatment with ethylene action inhibitors or the expression of a mutated ethylene receptor (etrl-1), do not exhibit pollinationinduced corolla senescence (Jones and Woodson, 1997; O'Neill et al., 1993; Wilkinson et al., 1997).

The induction of physiological and biochemical processes at sites distal to the site of pollen perception suggest a translocated signal which precedes the growing pollen tube signals a compatible

\footnotetext{
Received for publication 6 Nov. 1998. Accepted for publication 22 June 1999 Purdue University Office of Agricultural Research Programs publication 15872. This research was supported by grants from the U.S. Department of Agriculture/ National Research Initiative Competitive Grants Program (no. 92-37304-7867) and the American Floral Endowment. The cost of publishing this paper was defrayed in part by the payment of page charges. Under postal regulations, this paper therefore must be hereby marked advertisement solely to indicate this fact. ${ }^{1}$ Current address: Department of Horticulture and Landscape Architecture, Colorado State University, Fort Collins, CO 80523-1173.

${ }^{2}$ To whom reprint requests should be addressed; e-mail: woodson@purdue.edu.
}

pollination to the ovary and petals. Reports of sequential increases in ACC and ethylene within carnation floral organs following pollination have suggested that either may be involved in interorgan signaling in carnations (Jones and Woodson, 1997; Nichols, 1977; Nichols et al., 1983; Woltering et al., 1995; Woodson et al., 1992). Reid et al., (1984) provided evidence for ACC translocation in carnations by measuring the evolution of radiolabelled ethylene from petals after application of radiolabelled ACC to the stigma. In moth orchid (Phalaenopsis Blume sp.) flowers, the perianth produces ethylene following pollination despite the absence of detectable ACC synthase mRNAs or activity (O'Neill et al., 1993). These observations, coupled with the fact that increases in ACC oxidase transcripts and activity are detected in the petals following pollination provides evidence for translocation of ACC from the gynoecium to the perianth (O'Neill et al., 1993). O'Neill et al., (1993) suggested that this ACC is merely a substrate for ethylene biosynthesis and that ethylene is the actual pollination signal perceived by the various organs. This hypothesis is based in part on evidence that the induction of ACC oxidase mRNAs in the perianth following pollination is dependent on ethylene (O'Neill et al., 1993).

In carnations we have recently demonstrated that pollination induces increases in ACC synthase and ACC oxidase transcripts in the styles and petals (Jones and Woodson 1997, 1999; Woodson et al., 1992). In contrast, ACC synthase transcripts are not up regulated by pollination in the ovary despite significant pollination-induced increases in ethylene evolution (Jones and Woodson, 1999). To determine if ACC is synthesized in the ovary by an unidentified ACC synthase gene or if ethylene biosynthesis in the ovary relies on translocation of ACC from other floral organs, ACC synthase activity needs to be measured in the ovary following pollination.

In carnations, we have demonstrated previously that ethylene perception in the pollinated style is required for propagation of the pollination signal to the petals, and that ethylene biosynthetic genes in the ovary and petals are regulated by ethylene (Jones and Woodson, 1997, 1999). In light of this evidence we hypothesize that ethylene is the primary translocated signal in pollinated carnations. To begin to understand the role of ethylene in interorgan signaling, it is necessary to determine where in the flower ethylene is synthesized and which floral organs rely on translocated ACC for ethylene production. In this paper we report ethylene production rates, accumulation of the ethylene precursor ACC, and activity of ACC synthase in styles, ovaries, and petals following pollination. Through a series of dissection experiments we have also demonstrated the 
existence of a translocated pollination signal in carnations and determined the timing of this signal.

The relatively short life of cut flowers and flowering potted plants reduces their commercial value, restricts markets, and restricts the number of species in production. The postproduction quality of these crops is limited by flower senescence. While some flowers senesce in an ethylene independent manner, in many flowers of horticultural significance senescence is regulated by ethylene. Experiments similar to ones reported in this paper serve to increase our understanding of how ethylene regulates flower senescence and thereby provide information that can be used to improve the postproduction quality of high value flower crops.

\section{Materials and Methods}

Plant material. Greenhouse-grown carnations (Dianthus caryophyllus 'White Sim') were used in all experiments. Mature flowers were harvested at anthesis when the styles were elongated and receptive to pollination. 'White Sim' flowers were pollinated by brushing the stigmatic surface with pollen from freshly dehiscent anthers of 'Starlight' carnations. It has been shown previously in our laboratory that crosses between 'Starlight' and male sterile 'White Sim' carnations result in production of viable seed and induce premature corolla senescence (Larsen et al., 1995).

Treatment of OVARIES With Propylene. The ethylene analog propylene was used to demonstrate that a gaseous molecule could be translocated between the gynoecium and the petals of carnations. Propylene was applied into the carnation ovary at a concentration of $10 \mu \mathrm{L} \cdot \mathrm{L}^{-1}$ via a continuous flow system. Ten microliters per liter of propylene is not a biologically active concentration, but can be detected by gas chromatography and distinguished from endogenously produced ethylene. The continuous flow system consisted of a jar of $10 \mu \mathrm{L} \cdot \mathrm{L}^{-1}$ propylene containing coils of tubing that were gas permeable. This tubing was then connected on both ends to lengths of Tygon tubing which exited the jar. One end of the tubing terminated in a needle that was injected into the locule air space of the ovary. The other end of the tubing was used to initiate the flow of propylene by applying air briefly to the tubing and then clamping off the end. The propylene was then allowed to flow passively by diffusion into the carnation ovary.

ETHYLENE MEASUREMENTS. To determine the contribution of individual floral organs to pollination-induced ethylene production by the flower, the rate of ethylene production from stigma/styles, ovaries, and petals was measured. Hereafter the term style will be used to refer to a floral organ that includes the style and the stigmatic region, a tissue that is not morphologically distinct in carnations. At various times after pollination, flowers were dissected and floral organs were enclosed in 6-mL vials. Vials were capped with septa, incubated for $15 \mathrm{~min}$, and a 1-mL gas sample was withdrawn for analysis of ethylene. For ethylene determination, samples were injected into a gas chromatograph with an activated alumina column (Varian, Walnut Creek, Calif.). Floral organs from control (unpollinated) flowers were collected and analyzed similarly. Propylene evolution from individual petals was also determined using gas chromatography. To measure ethylene production from style sections, styles were removed from flowers at various times after pollination and cut into three sections. Top, middle, and bottom sections were then sealed in 6-mL vials for ethylene analysis. Each experiment presented in this paper utilized a replication of six flowers per pollination or control time point. For each flower all styles from the flower and four petals per flower were collected for ethylene measurements. Ethylene biosynthesis experiments were repeated three times within a 3-month period with similar results. Only the results of the first experiment are presented. Graphed values represent mean ethylene production \pm SE for the replications. Following ethylene measurements, tissues were weighed, quick frozen in liquid nitrogen, and stored at $-80^{\circ} \mathrm{C}$ until they were used for ACC and ACC synthase assays.

ACC AND ACC SYNTHASE ASSAYS. ACC accumulation was measured using the method of Lizada and Yang (1979). The concentration of ACC (nmol) was determined by comparing values to an ACC standard. ACC synthase activity was assayed as described by Yu et al., (1979) with modifications. Carnation tissue was powdered in liquid $\mathrm{N}_{2}$ and homogenized with a mortar and pestle in extraction buffercontaining 100mmHEPES-KOH(pH 8.0), 4 mmdithiothreitol (DTT), $5 \mu \mathrm{M}$ pyridoxal phosphate (PLP), and $30 \%$ (v/v) glycerol. The extract was centrifuged at $10,000 g_{\mathrm{n}}$ for $10 \mathrm{~min}$, and then filtered through two layers of cheese cloth. The supernatant was dialyzed overnight, with one change of buffer, in $2 \mathrm{~L}$ of dialysis buffer containing $10 \mathrm{~mm}$ HEPES-KOH (pH 8.0), $0.2 \mathrm{~mm}$ DTT, and $5 \mu \mathrm{M}$ PLP. After dialysis to remove endogenous ACC, $400 \mathrm{~mL}$ of extract was incubated with $100 \mathrm{~mL}$ of $200 \mathrm{~mm} \mathrm{SAM}$, and $100 \mathrm{~mL}$ of assay buffer (assay buffer was $100 \mathrm{~mm}$ HEPES-KOH, 4 mM DTT, and 5 $\mu \mathrm{M}$ PLP) for $1 \mathrm{~h}$ at $30^{\circ} \mathrm{C}$. Control reactions had $100 \mathrm{~mL}$ of water in place of SAM. The reactions were stopped on ice and $500 \mathrm{~mL}$ of the enzyme extract was then used in the ACC assay. One unit of enzyme activity was defined as that which converted $1 \mathrm{nmol}$ of SAM to ACC per h at $30^{\circ} \mathrm{C}$.

\section{Results}

Postrollination ReSPONSES In CARNATions. Ethylene production is first detectable from the gynoecium before visual symptoms of senescence. In pollinated carnation styles, ethylene biosynthesis can be defined temporally by three peaks (Fig. 1). This pattern of stylar ethylene biosynthesis has been described previously (Jones and Woodson, 1997; Larsen et al., 1995), but is included in this paper to provide direct comparison among ethylene, ACC, and ACC synthase activity within the same flowers. The first small peak of ethylene production occurs from 1 to $4 \mathrm{~h}$ after pollination. The second burst of ethylene from pollinated styles peaks at $12 \mathrm{~h}$ after pollination, and this is followed by a sustained peak of ethylene production from 24 to $48 \mathrm{~h}$ after pollination. At $36 \mathrm{~h}$ after pollination, ethylene production was $>800 \mathrm{~nL} \cdot \mathrm{g}^{-1} \cdot \mathrm{h}^{-1}$. Ethylene production by unpollinated control styles was below $15 \mathrm{~nL} \cdot \mathrm{g}^{-1} \cdot \mathrm{h}^{-1}$ throughout the experiment. Measurable increases in ACC were detected by $1 \mathrm{~h}$ after pollination in styles, and peaks of ACC were measured at 12 and 36 $\mathrm{h}$ after pollination corresponding to the peaks of ethylene production. Control styles showed no significant increase in ACC content from 0 to $72 \mathrm{~h}$. Increased ACC synthase activity following pollination slightly preceded the increases in ACC. In pollinated styles, the early ACC synthase activity measured at $6 \mathrm{~h}$ after pollination, corresponding to the second peak of ethylene, was significantly greater than the activity during the later peak. Low levels of ACC synthase activity $\left(2.1 \mathrm{nmol} \cdot \mathrm{g}^{-1} \cdot \mathrm{h}^{-1}\right.$ and below) were detected in unpollinated styles.

In ovaries isolated from carnations at various times after pollination, elevated ethylene production was first detected at 6 $\mathrm{h}$ after pollination (Fig. 2). This ethylene production increased to $120 \mathrm{~nL} \cdot \mathrm{g}^{-1} \cdot \mathrm{h}^{-1}$ at $24 \mathrm{~h}$ after pollination and then declined steadily. Ethylene production from control (unpollinated) ovaries remained below $5 \mathrm{~nL} \cdot \mathrm{g}^{-1} \cdot \mathrm{h}^{-1}$. Pollination-induced increases in ACC were also first measured at $6 \mathrm{~h}$ after pollination. ACC continued to increase and peaked at $48 \mathrm{~h}$. Levels of ACC detected in styles and ovaries 
were similar despite seven fold lower ethylene production rates by ovaries. No significant increase in ACC was measured from 0 to 72 $\mathrm{h}$ in unpollinated ovaries. At $0 \mathrm{~h}$ ACC synthase activity in ovaries was $0.7 \mathrm{nmol} \cdot \mathrm{g}^{-1} \cdot \mathrm{h}^{-1}$. After pollination, the activity of ACC synthase in ovaries decreased to below $0.2 \mathrm{nmol} \cdot \mathrm{g}^{-1} \cdot \mathrm{h}^{-1}$ from 3 to $72 \mathrm{~h}$. Unpollinated control ovaries had significantly higher ACC synthase activity than ovaries from pollinated flowers but showed no increase or decrease in activity from 0 to $72 \mathrm{~h}$.

In petals from pollinated carnations, ethylene production was first detected at $24 \mathrm{~h}$ after pollination, just before inrolling of the petal margins (Fig. 3). This ethylene production was sustained until the last measurement at $72 \mathrm{~h}$ after pollination. By this time the corollas had wilted. As was observed in ovaries, ethylene production by the petals following pollination was significantly less than that of styles on a fresh weight basis. Ethylene production by control

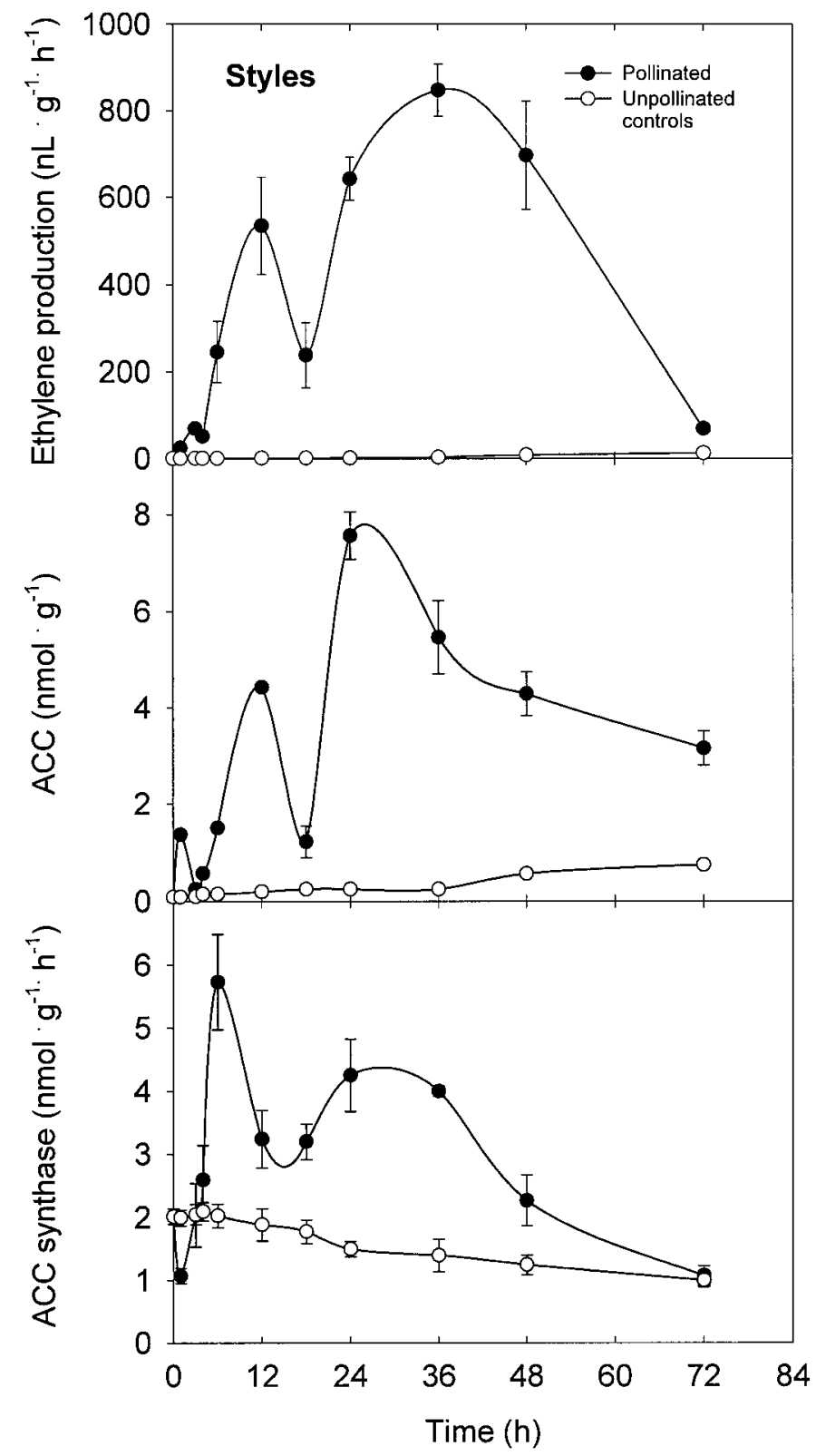

Fig. 1. Ethylene production, ACC, and ACC synthase activity from pollinated styles $(\bullet)$ and control styles from unpollinated flowers $(\bigcirc)$. Each time point represents the average value for styles from six flowers \pm SE. petals was barely detectable from 0 to $72 \mathrm{~h}$ with the highest rate of $3.7 \mathrm{~nL} \cdot \mathrm{g}^{-1} \cdot \mathrm{h}^{-1}$ measured at $72 \mathrm{~h}$. Accumulation of ACC peaked at almost $2 \mathrm{nmol} \cdot \mathrm{g}^{-1}$ at $48 \mathrm{~h}$ after pollination. This level of ACC was only one-third and one-fourth that measured from styles and ovaries respectively. No significant increase in ACC was measured in control petals. The rise in ACC synthase activity preceded the increase in ACC, peaking at $24 \mathrm{~h}$ after pollination. ACC synthase activity was detected in unpollinated petals but remained below 0.5 $\mathrm{nmol} \cdot \mathrm{g}^{-1} \cdot \mathrm{h}^{-1}$.

SPATIAL PRODUCTION OF ACC AND ETHYLENE WITHIN POLLINATED STYLES. To investigate the style as a potential source of ACC substrate for ethylene biosynthesis in the ovary, the spatial distribution of ACC and ethylene production within the style was determined by dissecting the style into three sections (top, middle, and bottom). The top section contained the stigmatic surface where

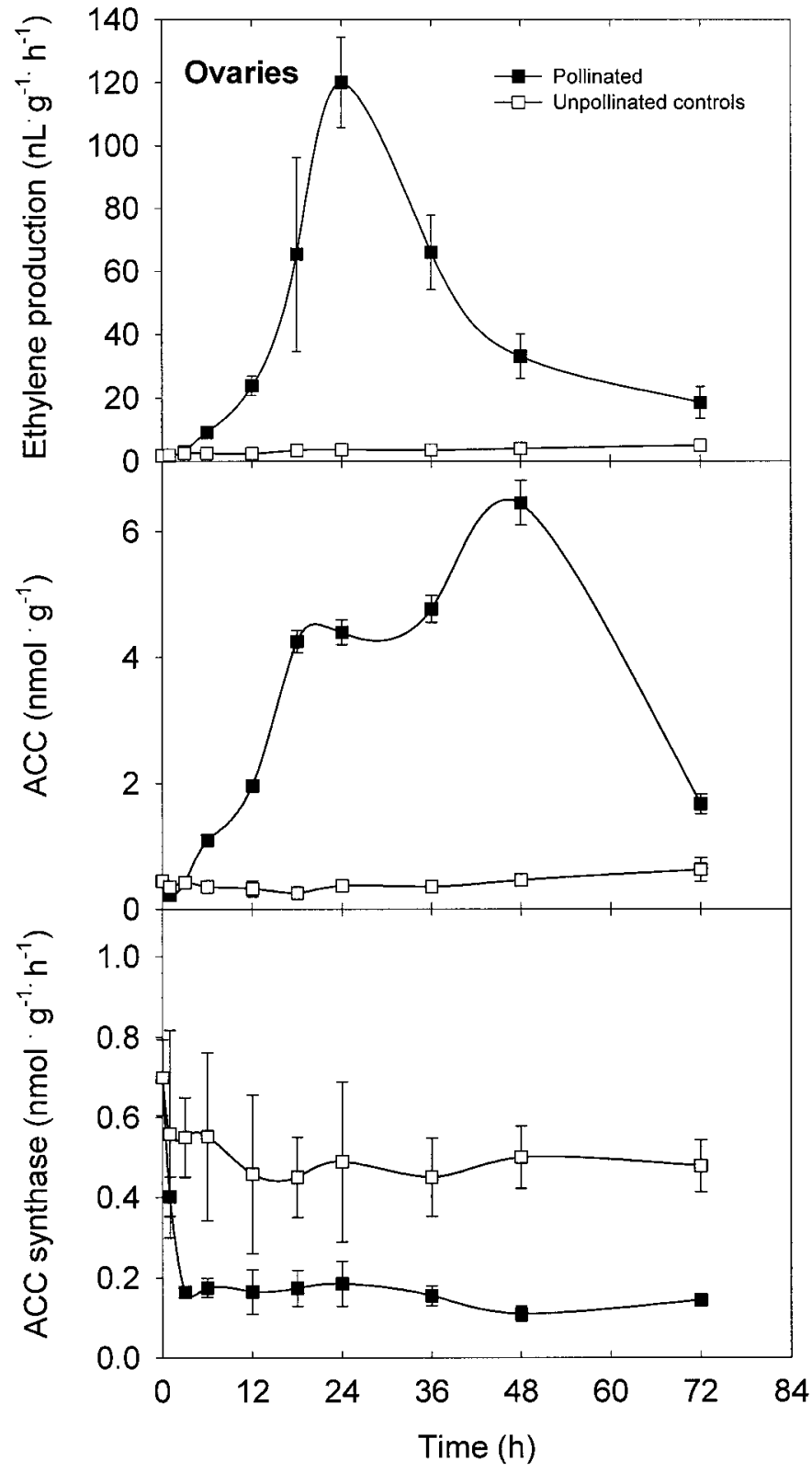

Fig. 2. Ethylene production, ACC, and ACC synthase activity from pollinated ovaries $(\mathbf{\square})$ and control ovaries from unpollinated flowers $(\square)$. Each time point represents the average value for six ovaries $\pm \mathrm{SE}$. 
pollen was applied. Figure 4A shows ethylene production from top, middle, and bottom style sections expressed as a percent of the ethylene production by the entire pollinated style. At $0 \mathrm{~h}$ (unpollinated control styles), ethylene production was slightly higher in top sections, but by $3 \mathrm{~h}$ after pollination the top section of the style was producing $>60 \%$ of the total stylar ethylene production. At $12 \mathrm{~h}$, the middle section produced the most ethylene, and by $24 \mathrm{~h}$ after pollination, $>80 \%$ of the pollinated styles' ethylene production was from the base of the style. A similar trend in ACC was measured, with the majority of the pollinated styles' ACC detected in the top section at $3 \mathrm{~h}$ after pollination and $>80 \%$ detected in the base by 24 $\mathrm{h}$ after pollination (Fig. 4B). The percentage of ACC and ethylene from unpollinated style sections at 3,12 , and $24 \mathrm{~h}$ was the same as control styles at $0 \mathrm{~h}$ (data not presented).

Timing The POLlination Signal. To investigate the timing of a

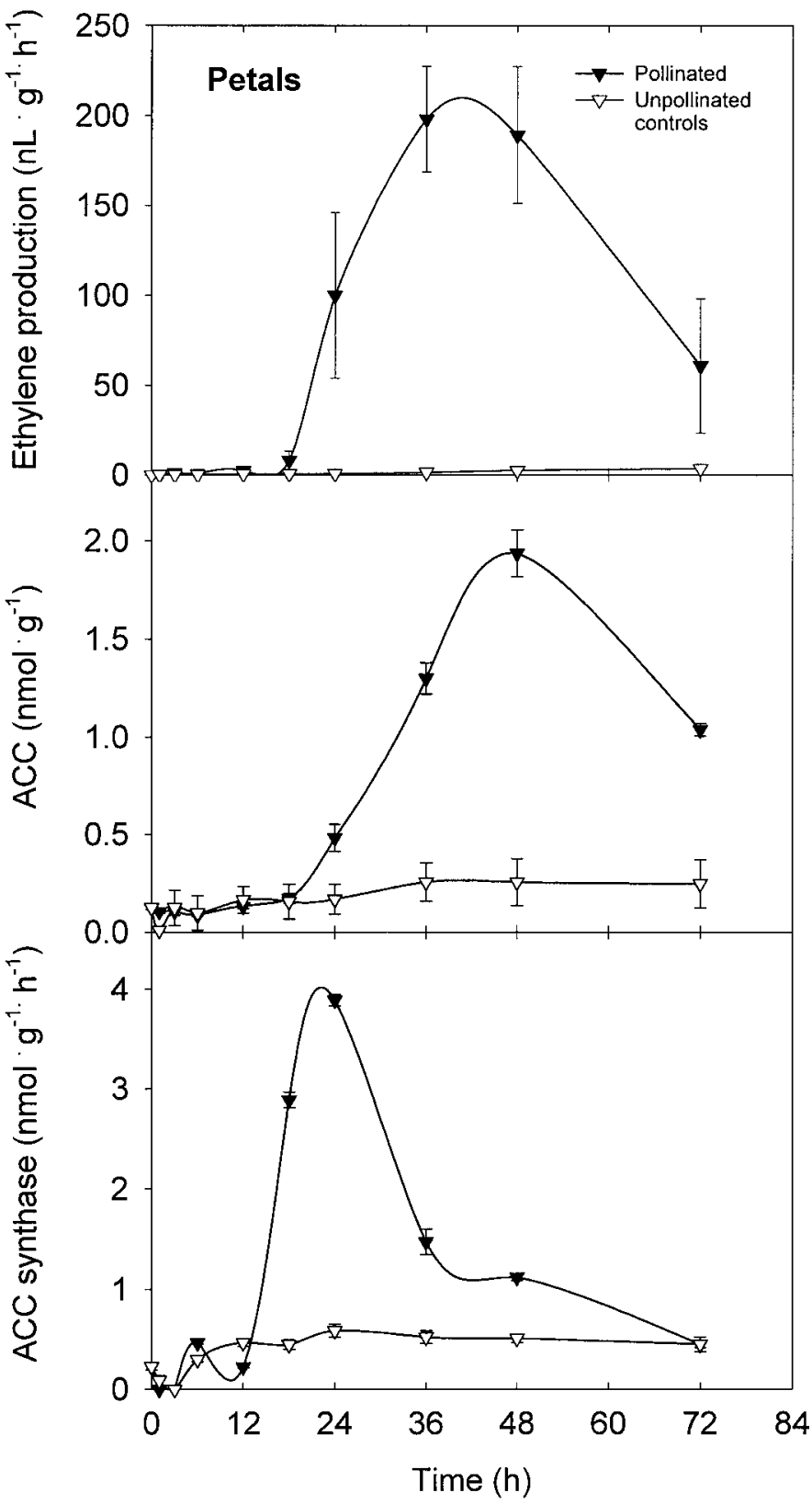

Fig. 3. Ethylene production, ACC, and ACC synthase activity from pollinated petals $(\boldsymbol{\nabla})$ and control petals from unpollinated flowers $(\nabla)$. Each time point represents the average value for petals from six flowers \pm SE. translocated pollination signal in carnations, pollinated styles or petals were removed at various times after pollination. When pollinated styles were removed at $8 \mathrm{~h}$ after pollination or earlier, none of the flowers exhibited accelerated corolla senescence (Fig. $5)$. When pollinated styles were removed at $10 \mathrm{~h}$ after pollination, $50 \%$ of the flowers exhibited premature petal inrolling. This increased to $80 \%$ to $100 \%$ at $12 \mathrm{~h}$ and later. In dissection experiments involving petals, ethylene production by the petals was measured when the petals were removed and again at $48 \mathrm{~h}$ after pollination when petals still attached to the flower were inrolling. After petals were removed, they were held with their bases in water in an
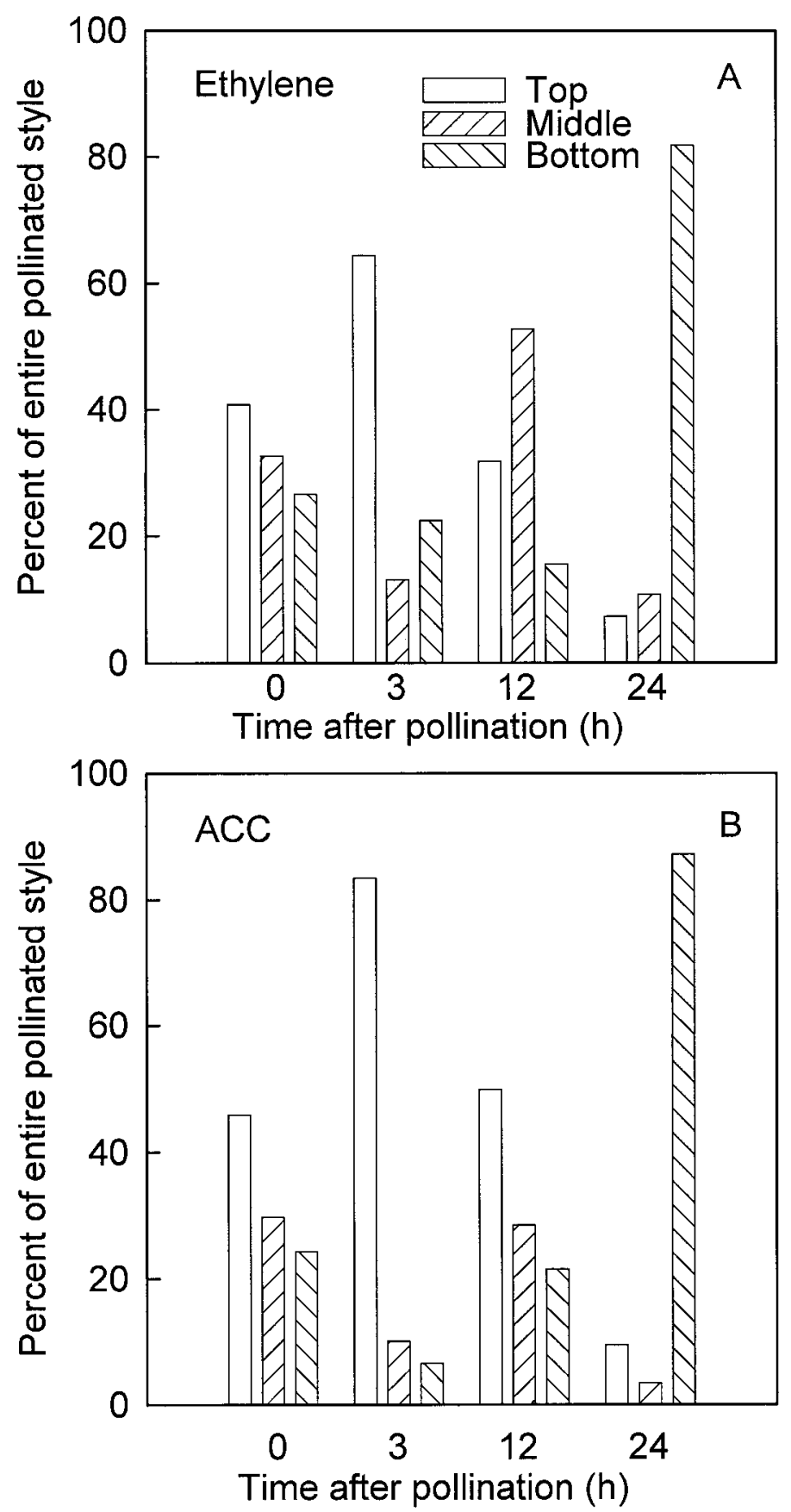

Fig. 4. Spatial production of (A) ethylene and (B) ACC within pollinated styles. Styles were removed from the flower at $0,3,12$, and $24 \mathrm{~h}$ after pollination, divided into three sections, and ACC and ethylene production from the sections was determined. ACC and ethylene production by style sections is presented as a percent of ACC accumulation or ethylene production by the entire style. 


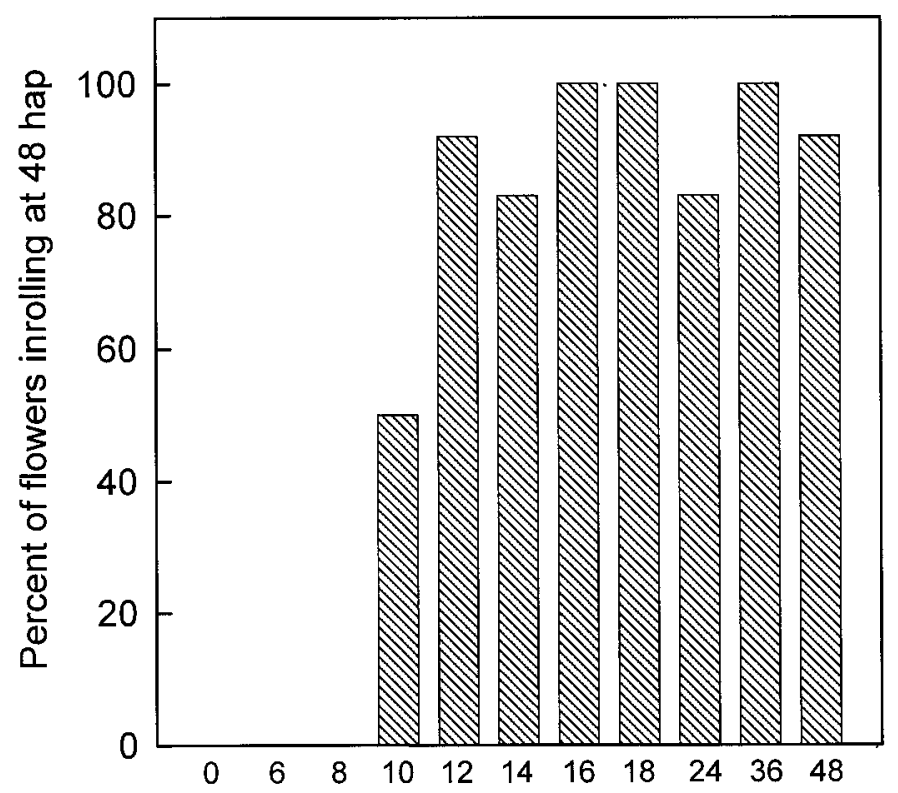

Time after pollination when styles removed $(h)$

Fig. 5 (above). Timing of the pollination factors translocation through the pollinated style. Pollinated styles were removed from flowers at various times after pollination. These flowers were maintained until $48 \mathrm{~h}$ after pollination (HAP) to determine which flowers exhibited pollination-induced senescence. This is presented as the percent of flowers inrolling at 48 HAP.

Eppendorf tube until $48 \mathrm{~h}$ after pollination. Petals removed from pollinated flowers at $12 \mathrm{~h}$ after pollination and earlier did not produce detectable levels of ethylene when they were isolated, or at $48 \mathrm{~h}$ after pollination (Fig. 6A). Moreover, these petals did not show any signs of inrolling at $48 \mathrm{~h}$ after pollination when intact petals were senescent (Fig. 6B). Petals removed at $14 \mathrm{~h}$ were not producing ethylene when removed, but were producing ethylene and inrolling when evaluated $48 \mathrm{~h}$ after pollination. Petals that were isolated at 16 or $18 \mathrm{~h}$ after pollination were also not producing detectable levels of ethylene when removed, but by $48 \mathrm{~h}$ after pollination had ethylene production rates higher than those measured from petals that remained on the pollinated flower until $48 \mathrm{~h}$. Unpollinated carnation petals isolated from the flower between 0 to $48 \mathrm{~h}$ did not produce detectable levels of ethylene (data not presented).

ETHYLENE AS THE TRANSLOCATED SIGNAL. To assess the ability of ethylene itself to be translocated from the ovary to the petals, the ethylene analog propylene was applied via a continuous flow system into the carnation ovary at a concentration of 10 $\mu \mathrm{L} \cdot \mathrm{L}^{-1}$. Petals were removed from the flower at various times after application of propylene and enclosed in a 6-mL vial for measurement of propylene. Propylene evolution from the petals was detected between 3 and $6 \mathrm{~h}$ after treatment initiation. The concentration of propylene obtained from single petals varied from 0.05 to $0.8 \mu \mathrm{L} \cdot \mathrm{L}^{-1}$ (data not presented).

\section{Discussion}

Pollination initiates many developmental events that are essential for successful reproduction. Signals that originate in the style at the site of pollination are translocated to the ovary and petals where they trigger ovary development and corolla senescence. In this paper we have presented differential regulation of ethylene biosynthesis in floral organs by measuring ethylene, ACC, and ACC synthase activity in styles, ovaries, and petals. These data in addition to what we have already reported about the differential expression of ethylene biosynthetic genes in floral organs provide a better understanding of how ethylene biosynthesis is regulated by pollination within different parts of the flower. Increases in ethylene biosynthesis were observed in all floral organs following pollination. In styles and petals ACC synthase and ACC oxidase transcripts are up regulated by pollination (Jones and Woodson, 1997, 1999; Woodson

Fig. 6 (below). Timing of the pollination factors translocation to the petals. Petals were removed from flowers at various times after pollination. Petals isolated from the flower were maintained with their bases in water until $48 \mathrm{~h}$ after pollination (HAP). (A) Ethylene production by the petals was measured when they were removed from the flower and at $48 \mathrm{HAP}$ when intact petals on pollinated flowers were inrolling. (B) Petals at 48 HAP. The numbering beneath the petals indicates the time after pollination when they were isolated from the flower.

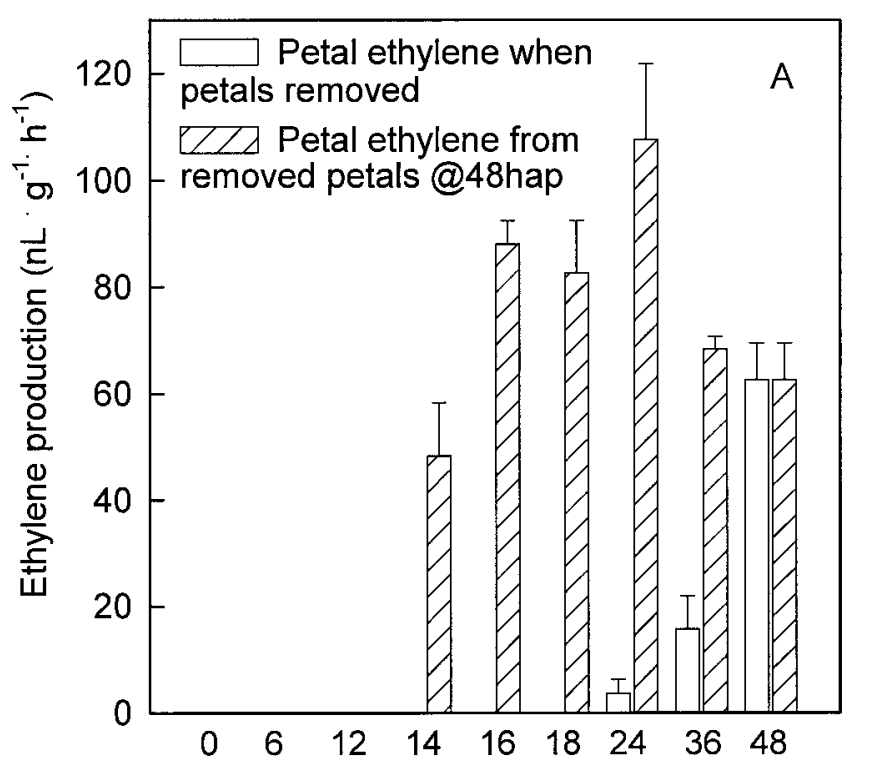

Time after pollination when petals removed $(h)$

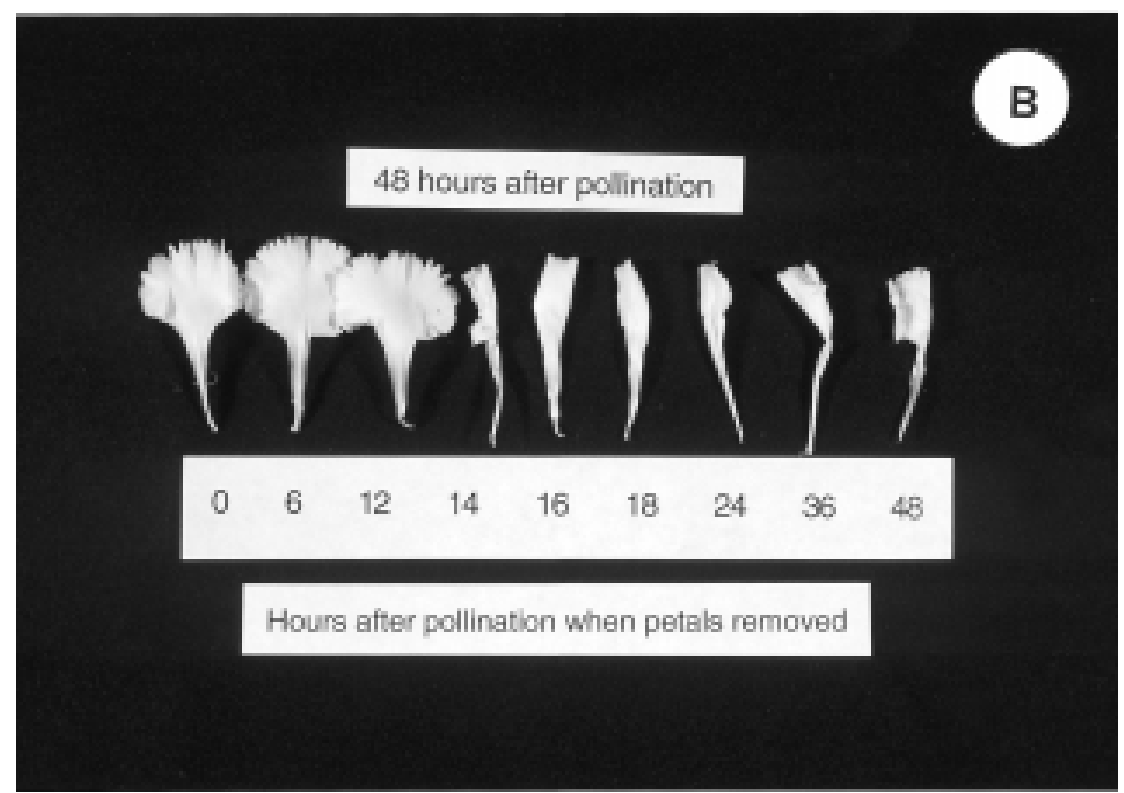


et al., 1992). While ACC oxidase transcripts are up regulated in ovaries following pollination, ACC synthase transcript abundance does not increase. Our ACC synthase enzyme activity data does not support the existence of other ACC synthase genes in the pollinated ovary but suggest ACC synthase is down regulated by pollination in ovaries. Differences in the levels of ACC synthase activity between the petals and styles did not correlate well with differences in the ethylene production rates of these two floral organs. This is difficult to reconcile without measuring the activity of the ACC oxidase in these organs. While ACC synthase is often considered to be rate limiting, ACC oxidase has also been found to limit ethylene production in senescing flowers (Yang and Hoffman, 1984).

Woodson et al., (1992) reported significant increases in ACC synthase activity in all organs (including ovaries) of 6-d senescing flowers. We have shown different results when measuring ACC synthase activity in ovaries from pollinated flowers. While pollination accelerates senescence of styles and petals, the ovary continues to grow and develop into a mature fruit. Despite these dramatic differences in development, pollination induces increased ethylene production from all floral organs. The differential regulation of ethylene biosynthesis observed in pollinated versus senescing ovaries may be a mechanism by which ethylene can regulate such different developmental processes.

When it was first shown that ACC and ethylene increased sequentially within the carnation flower it was proposed that translocation of ethylene and/or ACC throughout the flower served to propagate the pollination signal from the gynoecium to the petals (Nichols, 1977; Nichols et al., 1983). As a soluble hormone precursor it was thought that ACC was more amenable to targeted translocation than a gaseous molecule. In support of ACC as a translocated signal, transport of ACC has been reported to occur in the xylem and the phloem (Bradford and Yang, 1980; Hume and Lovell, 1983) and has been proposed as a mechanism for the interorgan regulation of ethylene biosynthesis in response to flooding (Bradford and Yang, 1980). Translocation of ACC within petals, from the base to the top, has been reported previously to occur in carnations (Overbeek and Woltering, 1990). Our recent studies with carnations have indicated that ACC translocation within the gynoecium provides ACC for ethylene biosynthesis in the ovary. By applying propylene to the carnation ovary we have also demonstrated that targeted translocation of a gaseous molecule from the gynoecium to the petals can occur. Similarly, ethylene applied to the central column of cymbidium orchid (Cymbidium Swartz sp.) flowers is readily translocated to the perianth (Woltering et al., 1995).

While there is ample evidence for translocation of ethylene and ACC between floral organs, these results provide only circumstantial evidence that either is the translocated pollination signal. For interorgan communication of the pollination event, all organs of the flower must perceive the pollination signal and this perception must result in the full postpollination syndrome. While ACC is translocated between floral organs this ACC most likely serves as a substrate for production of ethylene, the actual translocated signal. In experiments investigating the pollination-induced accumulation of ethylene biosynthetic genes in carnations, we have shown that induction of ACC oxidase transcripts in the ovary is dependent on ethylene (Jones and Woodson, 1997; Woodson et al., 1992). ACC synthase and ACC oxidase gene expression in petals following pollination is also regulated by ethylene (ten Have and Woltering, 1997; Jones and Woodson, 1997, 1999; Woodson et al., 1992). Treatment of pollinated carnations with inhibitors of ethylene action completely prevents postpollination events, including pollinationinduced gene expression and petal senescence (Jones and Woodson,
1997, 1999). Similar results have been observed in moth orchid flowers (Bui and O'Neill, 1998; O'Neill et al., 1993). This is consistent with the model proposed for moth orchid in which autocatalytic ethylene production by the flower is initiated by pollen-borne factors that induce ethylene biosynthetic genes in the stigma/style (Bui and O'Neill, 1998; O'Neill et al., 1993). In further support of this model, we have identified a pollination responsive ACC synthase gene in carnations (DCACS3) that is induced by pollination in styles independent of ethylene (Jones and Woodson, 1999). Subsequent increases in ethylene biosynthetic gene transcripts in the style are regulated by ethylene similarly to the regulation observed in ovaries and petals (Jones and Woodson, 1999). Consistent with the role of stylar ethylene in propagating the pollination signal to the rest of the flower, inhibiting ethylene action only in the style prevents all subsequent postpollination events in the ovary and petals (Jones and Woodson, 1997).

Similar to what has been reported in petunia (Petunia hybrida Hort) flowers (Gilissen and Hoekstra, 1984), we have demonstrated the existence of a translocated pollination signal in carnations using a series of dissection experiments. This pollination signal reached the ovary by 10 to $12 \mathrm{~h}$ and the petals by 14 to $16 \mathrm{~h}$ after pollination. We have demonstrated previously in carnations that ethylene production by the style from 3 to $18 \mathrm{~h}$ after pollination must be above a certain threshold level to induce autocatalytic ethylene production from the style, ovary, and petals (Jones and Woodson, 1997). If ethylene serves as the translocated signal in carnations, the times identified in our dissection experiments likely represent the amount of time required for enough ethylene to be perceived by the ovary and petals to induce ethylene biosynthetic genes and subsequently result in autocatalytic ethylene production from these organs. In ovaries, ACC oxidase transcripts and ethylene production can first be detected at low levels by $6 \mathrm{~h}$ after pollination with large increases in both observed at $12 \mathrm{~h}$ after pollination (Jones and Woodson, 1997). These observations fall into the time frame of a pollination signal initiating pollination events within the ovary by 10 to $12 \mathrm{~h}$ as was indicated by our dissection experiments. In petals, transcripts of ACC oxidase and ACC synthase are first detected at 12 and $18 \mathrm{~h}$ after pollination respectively (Jones and Woodson, 1997). Because these experiments did not include time points at 13 through $17 \mathrm{~h}$ after pollination, it should be noted that ACC synthase transcripts may be induced as early as $13 \mathrm{~h}$ after pollination. When carnation petals are treated with $2 \mu \mathrm{L} \cdot \mathrm{L}^{-1}$ exogenous ethylene, ACC oxidase and ACC synthase transcripts are first detected after 3 and $6 \mathrm{~h}$, while ethylene production by the petals is not detected until 9 to $12 \mathrm{~h}$ after treatment. The lag time of 6 to $9 \mathrm{~h}$ between induction of ethylene biosynthetic genes and ethylene production by the petals is similar to the lag time observed in our dissection experiments. By 14 to $16 \mathrm{~h}$ after pollination, ethylene produced by the gynoecium is translocated to the petals inducing transcription of ethylene biosynthetic genes. Ethylene production is then detected from the petals $\approx 8$ to $10 \mathrm{~h}$ later, at 24 $\mathrm{h}$ after pollination.

While less is known about the identity of the pollen factor that induces ethylene biosynthesis in the stigma, there is increasing evidence in carnations and moth orchid that ethylene serves as the translocated pollination signal. Identification of ACC synthase genes that are regulated by the primary pollination signal should provide a useful tool for identifying these pollen factors (Bui and O'Neill, 1998; Jones and Woodson, 1999). While regulation of ethylene biosynthetic genes by ethylene has been well studied, it is necessary to investigate the transcriptional regulation of these genes by ACC itself before the role of ACC in postpollination signaling can be understood. 


\section{Literature Cited}

Adams, D.O. and S.F. Yang. 1979. Ethylene biosynthesis: Identification of 1-aminocyclopropane-1-carboxylic acid as an intermediate in the conversion of methionine to ethylene. Proc. Natl. Acad. Sci. USA 76:170 174.

Borochov, A. and W.R. Woodson. 1989. Physiology and biochemistry of flower petal senescence. Hort. Rev. 11:15-43.

Bui A.Q. and S.D. O'Neill. 1998. Three 1-aminocyclopropane-1-carboxylate synthase genes regulated by primary and secondary pollination signals in orchid flowers. Plant Physiol. 116:419-428.

Burg, S.P. and M.J. Dijkman. 1967. Ethylene and auxin participation in pollen induced fading of vanda orchids. Plant Physiol. 42:1648-1650.

Bradford K.J. and S.F. Yang. 1980. Xylem transport of 1aminocyclopropane-1-carboxylic acid, an ethylene precursor, in waterlogged tomato plants. Plant Physiol. 65:322-326.

Gilissen L.J.W. and F.A. Hoekstra. 1984. Pollination-induced corolla wilting in Petunia hybrida rapid transfer through the style of a wiltinginducing substance. Plant Physiol. 75:496-498.

Hoekstra F.A. and R. Weges. 1986. Lack of control by early pistillate ethylene of the accelerated wilting of Petunia hybrida flowers. Plant Physiol. 80:403-408.

Hume R.J. and P.H. Lovell. 1983. Role of 1-aminocyclopropane-1-carboxylic acid in the control of female flowering in Cucurbita pepo. Physiol. Plantarum 59:324-328.

Kende, H. 1993. Ethylene biosynthesis. Annu. Rev. Plant Physiol. 44:283307.

Kende, H. and B. Baumgartner. 1974. Regulation of aging in flowers of Ipomea tricolor by ethylene. Planta 116:279-289.

Jones M.L. and W.R. Woodson. 1997. Pollination-induced ethylene in carnation. Role of stylar ethylene in corolla senescence. Plant Physiol. 115:205-212.

Jones M.L. and W.R. Woodson. 1999. Differential expression of three members of the ACC synthase gene family in carnation. Plant Physiol. 119:755-764.

Larsen P.B., E.N. Ashworth, M.L. Jones, and W.R. Woodson. 1995. Pollination-induced ethylene in carnation. Role of pollen tube growth and sexual compatibility. Plant Physiol. 108:1405-1412.

Lizada M-C.C. and S.F. Yang. 1979. A simple and sensitive assay for 1aminocyclopropane-1-carboxylic acid. Anal. Biochem. 100:140-145.

Mayak, S., Y. Vaadia, and D.R. Dilley. 1977. Regulation of senescence in carnation (Dianthus caryophyllus) by ethylene. Plant Physiol. 54:591593.
Nichols, R. 1966. Ethylene production during senescence of flowers. J. Hort. Sci. 41:279-290.

Nichols, R. 1971. Induction of flower senescence and gynaecium development in the carnation by ethylene and 2-chloroethylphosphonic acid. J. Hort. Sci. 46:323-332.

Nichols, R. 1977. Sites of ethylene production in the pollinated and unpollinated senescing carnation (Dianthus caryophyllus) inflorescence. Planta 135:155-159.

Nichols, R., G. Bufler, Y. Mor, D.W.Fujino, and M.S. Reid. 1983. Changes in ethylene production and 1-aminocyclopropane-1-carboxylate content of pollinated carnation flowers. J. Plant Growth Regulat. 2:1-8.

O’Neill, S.D., J.A. Nadeau, X.S. Zhang, A.Q. Bui, and A.H. Halevy. 1993. Interorgan regulation of ethylene biosynthetic genes by pollination. Plant Cell 5:419-432.

Overbeek, J.H.M. and E.J. Woltering. 1990. Synergistic effect of 1aminocyclopropane-1-carboxylic acid and ethylene during senescence of isolated carnation petals. Physiol. Plant. 79:368-376.

Pech, J-C., A. Latche, C. Larrigaudiere, and M.S. Reid. 1987. Control of early ethylene synthesis in pollinated petunia flowers. Plant Physiol. Biochem. 25:431-437.

Reid, M.S., D.W. Fujino, N.E. Hoffman, and C.S. Whitehead. 1984. 1aminocyclopropane-1-carboxylic acid (ACC) - The transmitted signal in pollinated flower? J. Plant Growth Regulat. 3:189-196.

Stead, A.D. 1992. Pollination-induced flower senescence: A review. Plant Growth Regulat. 11:13-20.

ten Have, A. and E.J. Woltering. 1997. Ethylene biosynthetic pathway genes are differentially expressed during carnation(Dianthus caryophyllus L.) flower senescence. Plant Mol. Biol. 34:89-97.

Wilkinson, J.Q., M.B. Lanahan, D.G. Clark, A.B. Bleeker, C. Chang, E.M. Meyerowitz, and H.J. Klee. 1997. A dominant mutant receptor from Arabidopsis confers ethylene insensitivity in heterologous plants. Nature Biotechnol. 15:444-447.

Woltering, E.J., D. Somhorst, and P. van der Veer. 1995. The role of ethylene in interorgan signaling during flower senescence. Plant Physiol. 109:1219-1225.

Woodson, W.R., K.Y. Park, A. Drory, P.B. Larsen, and H. Wang. 1992. Expression of ethylene biosynthetic pathway transcripts in senescing carnation flowers. Plant Physiol. 99:526-532.

Yang, S.F. and N.E. Hoffman. 1984. Ethylene biosynthesis and its regulation in higher plants. Annu. Rev. Plant Physiol. 35:155-189.

Yu, Y.B, D.O. Adams, and S.F. Yang. 1979. 1-aminocyclopropane-1carboxylate synthase, a key enzyme in ethylene biosynthesis. Arch. Biochem. Biophys. 198:280-286. 